\begin{tabular}{|c|c|c|c|}
\hline Socio-demographic Characteristics & & & Level of significance \\
\hline & & & $\mathrm{U}=2787.50$ \\
\hline & Female & $33.57 \pm 5.66$ & $Z=-0.782$ \\
\hline \multirow[t]{4}{*}{ Gender } & Male & $32.50 \pm 5.74$ & $p=0.434$ \\
\hline & 25 ve? & $27.00 \pm 3.55$ & \\
\hline & $26-30$ years & $32.34 \pm 5.79$ & \\
\hline & $31-35$ years & $34.85 \pm 5.88$ & $K W=12.000$ \\
\hline \multirow[t]{3}{*}{ Age group } & 36 ve? & $33.11 \pm 5.40$ & $p=0.007$ \\
\hline & Married & $33.58 \pm 5.70$ & \\
\hline & Single & $30.30 \pm 5.05$ & $\mathrm{KW}=11.02$ \\
\hline \multirow[t]{3}{*}{ Marital status } & Divorced & $37.75 \pm 2.62$ & $p=0.004$ \\
\hline & Nuclear family & $32.80 \pm 5.81$ & \\
\hline & Extended family & $34.60 \pm 4.87$ & $K W=5.159$ \\
\hline \multirow[t]{3}{*}{ Family type } & Single parent & $37.75 \pm 2.62$ & $p=0.076$ \\
\hline & & & $\mathrm{U}=1330.50$ \\
\hline & Yes & $33.85 \pm 5.51$ & $Z=-2.866$ \\
\hline \multirow[t]{4}{*}{ Do you have children? } & No & $30.25 \pm 5.62$ & $p=0.004$ \\
\hline & 1 & $33.57 \pm 6.05$ & \\
\hline & 2 & $33.86 \pm 5.54$ & \\
\hline & 3 & $35.40 \pm 3.93$ & $\mathrm{KW}=4.641$ \\
\hline \multirow[t]{4}{*}{ Number of children $(n=128)$} & 4 and more & $28.75 \pm 2.75$ & $p=0.200$ \\
\hline & Vocational school of health & $27.41 \pm 4.94$ & \\
\hline & Associate of science & $30.60 \pm 5.58$ & $\mathrm{U}=2094.50$ \\
\hline & Bachelor's degree & $35.83 \pm 4.30$ & $Z=-2.796$ \\
\hline Educational status & Other & $28.27 \pm 4.46$ & $p=0.005$ \\
\hline
\end{tabular}

chance for keeping the acquired attitudes, behaviour and habits in the following years is the highest. As in many subjects, giving the importance to sexual education in this period has many benefits regarding development. This descriptive study was carried out in order to determine knowledge levels and attitudes of doctors and nurses regarding children's sexual development and sex education.

Methods The design of the study is descriptive. The study was conducted with doctors and nurses who work at various clinics of two state hospitals located in the Istanbul province. A total of 138 doctors and 150 nurses work at these hospitals.

Results It was determined that the majority of cases were female and were aged more than 36 years. $63.5 \%$ of the cases have bachelor's degrees and $62.1 \%$ were medical doctors. It was determined that the number of correct responses given by the cases regarding some behaviours observed in children aged between 3-6 years and children's sexual development and sex education showed significant differences according to age group, marital status, status of having children, educational status, and occupation (Table 1).

Conclusions All of our cases think that it is necessary to provide sex education for children and the majority of cases think that sex education should be provided for children aged between 712 years.

\section{P0-0871 DISCHARGE MANAGEMENT MORE EFFECTIVE WHEN PARENTS PARTICIPATE}

${ }^{1} \mathrm{CJ}$ van der Perk, ${ }^{1} \mathrm{MGE}$ Jansen, ${ }^{2} \mathrm{MM}$ Maaskant, ${ }^{2} \mathrm{MI}$ van der Boon, ${ }^{2} \mathrm{E}$ Mout. ${ }^{1}$ Chirurgie and Zuigelingen H7Zuid, Academic Medical Center Women's and Children's Clinic, Amsterdam, Netherlands; 'Women's and Children's Clinic, Academic Medical Center, Amsterdam, Netherlands
Introduction Parents whose child is admitted in a hospital are often overwhelmed by an oncoming discharge. Especially when care has to be continued at home, parents instructions are provided only shortly before discharge. As a result discharge may be suboptimal or hospitalisation may be prolonged. The question arises whether family centred care contributes to a more effective and efficient discharge management.

Method We studied the literature, organised 4 focus group discussions with 21 nurses in total, and distributed a survey among 15 parent couples.

Results Results from several studies show that parents' participation reduces the time of hospitalisation by circa 3 days. In the focus group discussions nurses recognised that the moment of discharge is mainly based on medical criteria. As a result parents instructions start at a late moment, must be performed in a short period of time and sometimes increases the length of stay. The surveys showed that all parents feel responsible for the care of their child during hospitalisation. Of the parents, 64\% mentioned that they are involved in the discharge planning, that started at admission. However, only 34\% of the parents stated to be informed about discharge criteria.

Conclusion Parents' participation shortens the length of stay in hospital. However, the present discharge procedure is not sufficiently family centred and oncoming discharge is not discussed timely. We recommend to discuss discharge planning on a daily base within the team of care providers including the parents, and to involve parents in the discharge manangement.

\section{PO-0872 CASE MANAGEMENT IN PAEDIATRIC PALLIATIVE CARE}

A van der Tempel, AP Groenenberg, S Vallianatos. Women's and Children's Clinic, Academic Medical Center, Amsterdam, Netherlands 
Background Research shows that palliative care for children requires special attention and a coordinated approach to support the child and its entire family. In June 2012 a project was started in the Women's and Children's Clinic, Academic Medical Centre, Amsterdam, the Netherlands.

The aim of this project is to give a child with a life threatening or life limiting illness the highest possible quality of life and to relieve parents from all coordination tasks.

Methods We developed a multi-disciplinary team of professionals, called the Emma Home Team (EHT), to support families with a child in the palliative phase. A case manager (a paediatric nurse) visits the family at home and coordinates the care in collaboration with parents and professionals to provide a unique situation for each family.

When the treatment period has finished the case manager evaluates the care with the parents and professionals involved.

Results In the last 18 months over 90 families were supported by the EHT. In 32 cases the care is finished and evaluated. These evaluations all show the importance of the coordinating function of the case manager. Parents who were supported by the EHT indicated that the commitment, expertise and accessibility of the team were a great support for them.

Conclusion The interventions by the EHT seem to have an important added value for children and families in the palliative phase. A next step is to see if this way of caregiving can be used in other hospitals.

\section{PO-0873 DETERMINATION OF FALLING RISK FOR CHILDREN IN AN EDUCATION AND RESEARCH HOSPITAL IN TURKEY}

${ }^{1} \mathrm{D}$ Suluhan, ${ }^{2} \mathrm{G}$ Aktas, ${ }^{1} \mathrm{D}$ Yildiz, ${ }^{2} \mathrm{D}$ Konukbay, ${ }^{1} \mathrm{~B}$ Fidanci, ${ }^{3}$ I Sürer, ${ }^{4} \mathrm{~V}$ Kesik. ${ }^{1}$ School of Nursing Pediatric Nursing Department, Gülhane Military Medical Academy, Ankara, Turkey; ${ }^{2}$ School of Nursing, Gülhane Military Medical Academy, Ankara, Turkey; ${ }^{3}$ Pediatric Surgery Department, Gülhane Military Medical Academy, Ankara, Turkey; ${ }^{4}$ Pediatric Oncology Department, Gülhane Military Medical Academy, Ankara, Turkey

10.1136/archdischild-2014-307384.1497

Objective The aim of this study was to determinate falling risk ofchildren who have been in Gulhane Military Medical Academy Hospital.

Methods The study wascaried out at department of paediatric surgery and department of pediatricsbetween February-March 2014 in Gulhane Military Medical Academy Hospital. Thepopulation of the study was consisted of 122 children. Diagnostic Falling RiskScale for Child Patients were used for data collection.

Results In the study group $36.1 \%$ of patients were female and $69.9 \%$ were male. The majority of patients were $<3$ years of age $(32.8 \%)$. Thereasons having been in hospital in hospital included pulmonary disease (18.6\%),neurological or neuromuscular disorders $(13.7 \%)$, and cardiac disorders (2\%), complicationsof prematurity $(8.8 \%)$, inguinal region deformity (3\%), immunological disease $(5.9 \%)$, fluid and electrolyte disorders (3.8\%),poisoning (\%3) and cancer (27.5). It was $57.4 \%$ staying in hospital which isrange from one to seven days. It was found that falling risks were high levelwhich is $97.5 \%$. There wasno stastically important difference in falling risks between gender ( $p$ ?0.005).

Conclusion It was found high falling risk for children who have beenin our hospital.

PO-0874 WITHDRAWN

\section{Nursing Adolescent Health}

\section{PO-0875 BEING AN ADOLESCENT MOTHER: A QUALITATIVE RESEARCH}

T Ayyildiz Kuzlu, M Uzun, H Kulakçi, F Veren. Nursing, Bulent Ecevit University, Zonguldak, Turkey

\subsection{6/archdischild-2014-307384.1498}

Background and aims The aim of this study was to determine the thoughts of adolescent pregnants/mothers about motherhood.

Methods A descriptive qualitative approach was used in the study. The data were obtained from 41 adolescent pregnants/ mothers with a questionnaire and open-ended semi-structured interviews in-depth audio-taped method. Data were analysed through thematic analysis by researchers.

Results Over the total amont of sample; $80.5 \%$ of adolescents didn't use a family planning method, $24.4 \%$ are relatives with her husband, $68.3 \%$ were being pregnant willingly and $24.4 \%$ didn't receive antenatal care regulary. The theme of study determined on four topics;

1) The feelings when she learn her pregnanacy

2) The meaning of baby/child in her life

3) The effect of pregnancy for her future plans

4) The troubles about care of baby/child

They mentioned hearing about their pregnancy, the first feelings were fear, sadness, wonder, happiness, shocked, rebelled and thought it wasn't the right time.

"I really surprised and feared because being a mother seemed difficult for me. Because of economical obstacle I thought that could we support the babies'care expenditure."

"I got married when I was 18. Everyone began to ask whether I am pregnant in first month period of my marriage. After three month I got pregnant. I felt that I had to be pregnant"

"I felt sadnesss, really a big sadness, cry too much, because my husband had left the house just before the news of pregnancy."

Conclusion Although pregnancy is gratifying process for a woman, it can also become discomfortable situation for adolescents.

\section{PO-0876 PEER BULLYING: KAPADOKYA IN TURKEY}

'D Evgin, ${ }^{1} \mathrm{Z}$ Caliskan, ${ }^{2} \mathrm{M}$ Bayat, ${ }^{1} \mathrm{~N}$ Goktas, ${ }^{1} \mathrm{~B}$ Kaplan, ${ }^{3} \mathrm{~A}$ Ozturk, ${ }^{2} \mathrm{D}$ Keklik. ${ }^{1}$ Nursing, Nevsehir University Semra and Vefa Küçük College of Health, Nevsehir, Turkey; ${ }^{2}$ Nursing, Erciyes University Faculty of Health Sciences Department of Nursing, Kayseri, Turkey; ${ }^{3}$ Biostatistics, Erciyes University Faculty of Medicine Department of Biostatistics, Kayseri, Turkey

\subsection{6/archdischild-2014-307384.1499}

Introduction and aim Violence is a widespreading social problem including school aged children and adolescents in Turkey as everywhere in the world. The present study was conducted descriptively to determine the prevalence of bullying among 6th, 7 th and 8 th graders in secondary schools of a city province in Turkey.

Method Universe of the study consists of 3059 students attending secondary schools in Nevsehir province in Turkey. Randomly selected 1287 students were recruited in this cross-sectional study. Ethical approval and institutional permission were 